\title{
De la calle a vidas extraordinarias: entrevistas y perfiles de José Antonio Osorio Lizarazo*
}

\author{
Claudia Darrigrandi Navarro**
}

\section{Resumen}

En el siguiente artículo se analiza la construcción biográfica por medio de entrevistas y perfiles del trabajo del escritor y periodista colombiano, José Antonio Osorio Lizarazo (19001964). El foco está puesto en la década del veinte, cuando publica entrevistas-reportajes dedicados a ciertos personajes de la ciudad en el periódico gráfico Mundo al Día; y a finales de la década del treinta, cuando a partir de las entrevistas, retoma estas figuras y escribe los perfiles que fueron publicados en El Tiempo. Se arguye, entonces, que la reescritura de estas vidas en forma de perfil cumple no solo un fin periodístico-literario sino que se trata de un medio para articular una crítica al partido liberal de ese período.

Palabras clave: José Antonio Osorio Lizarazo, perfiles, espacio biográfico, entrevistas.

\section{From the streets to extraordinary lives: José Antonio Osorio Lizarazo's Interviews and Profiles}

\begin{abstract}
This article discusses José Antonio Osorio Lizarazo's interviews and profiles as biographical constructions. During the 1920's Osorio Lizarazo (1900-1964), a Colombian journalist and writer, published interviews and reportages about urban characters in the journal Mundo al Día. More than ten years later he wrote profiles about some of these same characters, but in this opportunity they were published in El Tiempo. Therefore, this article argues that these profiles belong to his journalist and literary repertoire but also are a mean to articulate his criticism to the liberal party.
\end{abstract}

Keywords: José Antonio Osorio Lizarazo, profiles, biographic space, interviews.

\footnotetext{
* Este trabajo ha sido realizado en el marco del proyecto Fondecyt iniciación № 11140881 , del cual la autora es la investigadora responsable.

** Chilena, Doctora en Literatura por la Universidad de California, Davis. Directora de CIDOC, Universidad Finis Terrae. cdarrigrandi@uft.cl
} 
En el comienzo de "Las vidas sencillas y extraordinarias. Cuchuco", publicado en el diario El Tiempo el 28 de abril de $1940^{1}$, se hace alusión a un tiempo pasado y se señala la escritura de una vida que ya ocurrió: "Hubo un tiempo en que Juan de Jesús Flórez fue una figura central de la vida bogotana. Su silueta patizamba, su rostro abotagado y socarrón se impusieron como un hecho característico de la ciudad" (371). Esa es la forma en la que el periodista, José Antonio Osorio Lizarazo (1900-1964), ${ }^{2}$ introducía a sus lectores a la vida de Cuchuco, una figura urbana, que junto a tantos otros personajes de la ciudad le interesaron tanto para su escritura periodística como para su escritura literaria.

Pero esta vida sencilla y extraordinaria de Cuchuco, plasmada en un perfil, fue antes, varios años antes, una entrevista con carácter de reportaje $^{3}$. Edison Neira, en su estudio sobre Bogotá en la obra de Osorio Lizarazo, enfatiza el interés del escritor por estos sujetos urbanos y, entre ellos, destaca también a Cuchuco, uno de los varios personajes que son entrevistados por el periodista colombiano para el semanario gráfico Mundo al Día. Sin embargo, el giro que interesa constatar en las siguientes páginas es el paso de la entrevista-reportaje, dedicada a estos sujetos, a la escritura del perfil. Este cambio de formato, mediado por alrededor de diez años, señala un cambio en la valoración o cualidad de los personajes que son objeto de la pluma del cronista colombiano. Estos pasan de ser, en su mayoría, figuras urbanas a -si bien todavía urbanos-, sujetos destacados, principalmente, como actores políticos, de izquierda y revolucionarios, con vidas excepcionales, a pesar de pertenecer a una masa o a una incipiente clase media. De este modo, este grupo de personajes perfilados adquiere cierta singularidad dentro de los múltiples vínculos que los unen.

Osorio Lizarazo, novelista, periodista, empleado público, escribió reportajes y crónicas con un claro tinte biográfico. Entre esta producción

1 Todos los perfiles publicados en el periódico El Tiempo que se citan en este artículo fueron compilados por Santiago Mutis en el libro Novelas y crónicas (año). Las citas provienen de esa antología. 2 La labor como escritor y periodista de Osorio Lizarazo es bastante nutrida, escribió reportajes, crónicas, ensayos, estudios, novelas. También fue fundador de periódicos como El Heraldo de Barranquilla, fue director de El Diario. En los años treinta se desempeñó como jefe de redacción de otros medios y colaboró en periódicos y revistas de variado carácter. Esta amplia y diversificada participación en los medios escritos lo hace un sujeto interesante para estudiar cómo se han desarrollado distintos géneros escriturarios.

3 Según Edison Neira (2004), en su libro La gran ciudad latinoamericana: Bogotá en la obra de José Antonio Osorio Lizarazo, estos textos fueron publicados en la sección "Crónica de Osorio Lizarazo" donde "el autor alternaba entrevistas [...] con crónicas sobre la aviación en Colombiana [...], la fotografía [...] y notas literarias [...], donde insiste en la problemática de la transición" (cursivas en el original; 80). 
destaca una serie de personajes que el historiador colombiano Óscar Iván Calvo Isaza (2013) llama las "biografías de nadie”, y la "Biografía de una crisis política”. También es autor de textos de más largo aliento que se inscriben claramente dentro de lo que se reconoce como biografía, por ejemplo, la dedicada a Jorge Eliécer Gaitán, titulada Gaitán: vida, muerte y permanente presencia, publicada en 1952, y la centrada en el dictador dominicano, Así es Trujillo de 1958. También escribió una Biografía del café (1945). Si bien estas escrituras son parte del repertorio escritural del autor, esta recurrencia a la biografía es, asimismo, una metodología para instalar una voz. En particular, en las siguientes páginas se arguye, siguiendo lo ya propuesto por Calvo Isaza, que los reportajes de ciertos sujetos, al parecer insignificantes a finales de la década del veinte son reescritos, en forma de crónica, a finales de los treinta e inicios de los cuarenta para manifestar un descontento contra la República Liberal y sus líderes. Sin embargo, a diferencia del historiador colombiano, en este artículo se plantea que esa reescritura enfatiza ciertos aspectos de estas vidas para destacar valores relevantes para la clase media profesional en cuanto dominan oficios y saberes y, por lo tanto, les otorga cierta autoridad que los convierte en figuras importantes para la articulación de una efectiva crítica del liberalismo.

La escritura de la crónica junto con la escritura de perfiles han seguido caminos paralelos, se han cruzado, se han imbricado. Asimismo, se han distanciado. La escritura de perfiles se ha extendido a la escritura del ensayo y al reportaje. Obituarios, homenajes, reseñas como también críticas literarias, de cine o de música han ubicado, muchas veces en el centro de la narración, a la persona, al productor, al creador, al artista o al bohemio. Estos textos se han apropiado de fragmentos de vida, privada o pública, profesional, literaria o cultural, y dan cuenta de datos y acontecimientos relevantes para construir un personaje, presentar un personalidad o para insertar a una figura en un área del saber o en sus respectivos campos. Lugar de nacimiento, antecedentes familiares, ciudades habitadas, viajes, estudios, cargos desempeñados, trabajo creativo, producción intelectual, vida privada, chismes, y vida pública se mezclan con las descripciones de cuerpo, rostro, semblante, personalidad, genio o carácter. El perfil cubre, a veces, un momento de la persona "perfilada", la ubica en un escenario, se apropia de ella por fragmentos, intenta, ilusamente, capturar su carácter, explicar su excepcionalidad, su monstruosidad o su lucidez. Para los propósitos de este artículo, los perfiles son considerados parte del repertorio 
de los textos que componen el "espacio biográfico" entendido como una "confluencia de múltiples formas, géneros y horizontes de expectativas" (49) en términos de Leonor Arfuch, quien señala esta precisión en su libro El espacio biográfico. Dilemas de la subjetividad contemporánea (2010), al realizar una crítica a la propuesta de Philippe Lejeune.

Como señalaba unos párrafos atrás, antes de escribir esas biografías de prominentes figuras políticas, Osorio Lizarazo tuvo también una predilección por la escritura de vidas de personas, supuestamente, comunes y corrientes, invisibles o marginales. En 1926, Germán Arciniegas edita y publica una serie de crónicas bajo el título La cara de la miseria. En estas se recorren espacios urbanos tales como manicomios, hospitales, cárceles, conventillos, lupanares, entre otros tantos caracterizados por la marginalidad, todos ellos están acompañados por un grabado del retrato de los personajes de los que da cuenta cada crónica. En ese contexto, en La cara de la miseria, Osorio Lizarazo captura un "estado moral" de un grupo de personas, son instantáneas que se construyen por medio de gestos, rostros, prácticas y marcas de vida. Mientras se publicaba este libro, entre 1924-1927 el tabloide Mundo al Día, especializado en noticias gráficas, publicó una serie de reportajes-entrevistas que luego fueron reescritos para ser publicadas nuevamente en el diario El Tiempo, entre 1939-1940. Los que fueron publicados en la década del veinte tuvieron otros títulos y en algunos casos el reportaje está muy marcado por la entrevista. De este modo, las entrevistas funcionan como una versión preliminar para la construcción de los futuros perfiles que saldrán en $E l$ Tiempo. La entrevista es, por un lado, parte de la metodología necesaria para extraer la información sobre el potencial biografiado. Por otro lado, esa conversación sostenida entre el periodista y el personaje protagonista de su reportaje, expuesta en la prensa, también se constituye como en un espacio para la construcción biográfica. Arfuch plantea que la entrevista no ha sido estudiada en profundidad como espacio de construcción (auto)biográfica (120). Asimismo, señala que:

[c]omo género biográfico -aun cuando no se la considere habitualmente entre los 'canónicos' - que presenta vidas diversamente ejemplarizadoras, por excelencia o por defecto, lo es también de educación, aspecto modélico por antonomasia. [...] Hablando de la vida o mostrándose vivir, el entrevistado, en el juego dialéctico con su entrevistador, aportará siempre, aun sin proponérselo, al 'acervo' común. (118-119) 
Las figuras entrevistadas por Osorio Lizarazo, en esa primera instancia, no tienen ese carácter ejemplificador, lo serán en su segunda versión, en los perfiles publicados en El Tiempo. En tanto entrevista “[...] mantiene [...] vigentes los rasgos que quizá fueron la clave de su éxito inicial: la ilusión de la presencia, la inmediatez de sujeto en su corporeidad [...], la vibración de una réplica marcada por la afectividad -la sorpresa, la ira, el entusiasmo [...]" (119). Por su parte, Edison Neira (2004), señala que Osorio Lizarazo también se vio presionado por las nuevas demandas de la prensa comercial, como Mundo al Día, el semanario donde publicó en la sección “Crónica de la semana” las entrevistas recién mencionadas, y su trabajo se vio "afecta[do] por un cierto sensacionalismo" (79). Una muestra de lo anterior es el inicio de la entrevista-reportaje a Julia Ruiz, en la cual destaca el ambiente en que habita su personaje, así como también enfatiza el tiempo presente, de esta forma, traslada al lector al lugar mismo donde ocurrió el encuentro entre el reportero y la entrevistada: "Nadie creería que en el fondo de ese cuartucho, donde se aglomeran muebles usados y donde innumerables baratijas se muestran en promiscuidad de prendería, se ocultase tan formidable poder" (Osorio Lizarazo, "Se prepara una contienda" 22). Esta descripción inicial se diferencia del perfil publicado el año 1939, que comienza con la noticia de la muerte de Julia Ruiz y en el que se borra toda seña del presente. En el mismo texto ya citado, el periodista continúa con las marcas de aquello que podría generar cierta expectación entre los lectores, pues Ruiz ofrece "confesiones" y frases "desconcertantes" (22). Asimismo, aprovecha de jactarse sobre lo bien que practica su oficio: "Mis preguntas le han hecho contarme una parte de su historia” (22) y reitera, en varias ocasiones, la oportunidad de generar expectativas y emociones en sus lectores: “-La carestía que ahora se confronta cesará pronto [dice Ruiz]. - ¿Muy pronto? -interrogué con afán" (23). Distinto ocurre en "La vida misteriosa y sencilla de Julia Ruiz", texto en el que el periodista da paso a la revisión de su vida. En ese perfil, publicado originalmente en El Tiempo, la entrevista desaparece totalmente": "Julia Ruiz, la pitonisa o adivina que acaba de fallecer en la ciudad, es un bello personaje para una novela en la cual se reúnan la picaresca de los tiempos clásicos y las investigaciones clínicas de los anormales" (314-317). Similar ocurre en el caso Cuchuco que, en su primera versión, es un reportaje en el que se entrevista a un hombre

4 En otros de los perfiles publicados en El Tiempo no se elimina del todo la formulación de preguntas. 
que ha participado de guerras, ha trabajado con cónsules, ha vendido periódicos y ha repartido propaganda. Esta entrevista comienza, como ocurre en la que le hizo a Julia Ruiz, describiendo el entorno y el espacio donde ocurre la conversación: “Está ‘Cuchuco’ frente a mí escritorio, picaresco y socarrón” (“Un Sancho bogotano” 15). En cambio, totalmente diferente es el inicio de la reescritura de este personaje para el diario $E l$ Tiempo, cuando el carácter de perfil y de escritura biográfica se hacen más explícitos.

Calvo Isaza también ha señalado que estas escrituras de vida fueron borradores, estudios para la elaboración de los personajes de sus novelas y, en la cita recién mencionada, se manifiesta explícitamente esa idea que, además, refuerza la distinción entre la escritura referencial e informativa, de la ficcional:

Las Biografías de nadie son borradores para construir personajes de novela social. Son una serie de crónicas dedicadas a rescatar los perfiles biográficos de sujetos depreciados por los periodistas y los historiadoras de la época cuando se preguntaban ¿quiénes son los colombianos? y ¿qué significa ser colombiano? (s/p, párrafo 22)

Aunque estos reportajes, y los posteriores perfiles, sirvieron de ensayo para la construcción de los personajes de las novelas de Osorio Lizarazo, la reescritura de las vidas de estas personas son fundamentales para la articulación de su crítica al liberalismo, asunto que también es abordado por el historiador. Sin embargo, al menos en los textos consultados, no se detiene en explicar en detalle cómo se articula esa crítica. De este modo, la escritura biográfica se convierte en "recurso biográfico", y aquí se hace eco de lo planteado por Paula Bruno (2012), quien dice que desde este punto de vista, "la biografía [es] un medio más que [...] un fin" (157).

Interesante es la lectura que hace el historiador al contextualizarla en el debate sobre la nacionalidad, en un período, las décadas de los veinte y los treinta, en que en otros países los intelectuales igualmente se estaban preguntando por sus propias nacionalidades. Así también se han leído muchas de las crónicas de Roberto Arlt y de Joaquín Edwards Bello, o de Raúl Scalabrini Ortiz, quien escribió el ensayo El hombre que está solo y espera (1931). En ese texto, Scalabrini reflexiona sobre la identidad del hombre argentino, la que, para el ensayista, "se 'encuentra' en pleno centro de la capital, en la esquina de Esmeralda y Corrientes" 
(Darrigrandi 101). A diferencia del sello espacial de Scalabrini Ortiz, son otras las categorías que Osorio Lizarazo ensalza en sus biografiados: son sus acciones, lo que hicieron en su vida, lo que señalará la diferencia. En ese sentido, apela a un "hacer" versus un "ser". Por su parte, Eduardo Devés (2000) afirma que en una gran parte de la primera mitad del siglo $\mathrm{XX}$, desde el punto de vista del pensamiento latinoamericano, se produce una "oleada identitaria" que en la década de los veinte tuvo un marcado carácter social (97).

"Hubo un tiempo, muy próximo a nosotros, en que la simple enunciación de la posibilidad de que existiesen en Colombia problemas sociales constituía un delito" ("La vida extraordinaria de Jacinto Albarracín" 426). Así abre la crónica dedicada a Jacinto Albarracín, “quien nació en Arauca [Colombia] y nació revolucionario", señala Osorio Lizarazo. Con este perfil, el escritor colombiano abre el conjunto de crónicas dedicadas a hombres cuyas vidas habían transcurrido, principalmente, bajo el período conservador $\mathrm{y}$, como ya se ha señalado, fueron publicadas en El Tiempo. Este inicio, vuelve a dar cuenta de la escritura de una vida ya transcurrida, a diferencia de los reportajes de Mundo al Día y, si se dialoga con lo planteado por Devés, destaca el aspecto social de los habitantes de la capital colombiana y el espíritu combativo del sujeto biografiado. En suma, sería limitante pensar esas escrituras solamente como "borradores" o "laboratorio" para otras escrituras u obras, entre comillas, mayores, como ha sido entendida la novela. Otros escritores, ya sea de la historia, de la literatura o del periodismo, optaron también por escribir de personas corrientes, como lo hizo el historiador inglés Eric Hobsbwam en su libro Gente poco corriente. Resistencia, rebelión y jazz (1999), aunque a diferencia del gesto de Osorio Lizarazo, el historiador inglés lo hace para demostrar "más bien que, si no como individuos, colectivamente estos hombres y mujeres son actores importantes en la historia. Lo que hacen y piensan tiene importancia" (7). En ese mismo sentido, para el caso del periodista colombiano, es necesario preguntarse, una vez más, ¿Por qué esas vidas y no otras? ¿Cuál es el sentido de publicarlas como una serie? ¿Por qué reescribirlas y publicarlas otra vez?

De ese grupo de crónicas que Calvo Isaza denomina "Biografías de nadie" que se oponen a las que el identifica como "biografías de alguien", para el caso de Gaitán y Trujillo, cinco son vidas extraordinarias, aunque una es realmente una "vida sencilla y extraordinaria". Las otras no alcanzan a formar una serie, solo existe una "vida ilusionada", una "vida 
misteriosa" y una "vida humilde". Otras no reciben un encabezado que las clasifique. Fueron publicadas en la segunda sección de los días domingo del periódico El Tiempo, la que funcionaba como el apartado cultural de la semana donde se publicaban reportajes, cuentos, ensayos y crónicas. $E l$ Tiempo, periódico que fue fundado en 1911 por Alfonso Villegas Restrepo, adherente a la Unión Republicana, para el año1920 ya tenía un tiraje de más de diez mil ejemplares de ocho páginas, mientras que en la década del cincuenta se distribuían doscientos mil ejemplares (Melo). Con el arribo de Eduardo Santos a la dirección de El Tiempo, el diario fue adscrito al ideario del Partido Liberal, que en esa época era la oposición (Op. Cit.). Los años veinte todavía eran tiempos de la era conservadora que había comenzado en 1886. Santos llegó a la presidencia el año 1938, un año antes de la segunda escritura de las "biografías de nadie", y no dejó la propiedad del periódico. Aunque estaba al servicio de los liberales, "La definición de El Tiempo como el representante máximo de ciertas oligarquías políticas, capaces de manejar al país desde sus salas editoriales, se hizo común desde la década del 30 y ha durado hasta nuestros días", señala Jorge Orlando Melo (s/p, párrafo 3).

Calvo Isaza señala que Osorio Lizarazo nunca expresó interés en que esas "vidas" fueran rescatadas de los periódicos y publicadas en una antología. En este contexto parece interesante reflexionar sobre la decisión de republicarlas más de diez años después de su primera aparición. Para Edison Neira, “[f]ragmentarias o curiosas, muchas de sus crónicas tuvieron el propósito de hacer más concebible el presente a partir del pasado" (81). Como ya hemos señalado, de su primera a su segunda publicación, adquirieron otro carácter, el de ser "vidas", algunas "extraordinarias", otras "humildes" o "sencillas". Antes no eran vidas, eran reportajes sobre personas marginadas cuyas vidas estaban en progreso, no estaban acabadas y si bien no dejaban de ser personajes curiosos o dignos de interés por sus poderes sobrenaturales ${ }^{5}$, por sus intereses fuera de lo común o sus acciones revolucionarias, todavía no era posible hacer un balance, marcar una trayectoria, es decir, intentar escribir una vida, por muy arbitraria que esta sea. De este modo, el gesto del cronista coincide con el del historiador inglés, Hobsbwam, en convertir las vidas de personas

5 Por mencionar algunos ejemplos, Tulio F. Sánchez es Doctor en divinidades ("El hombre que podría salvar el país" 23), Biófilo Panclasta "ha vivido veinte años de bohemia anárquica" ("Perseguido por todos los gobiernos" 12); Efraím de la Cruz ha tenido una vida inarmónica según versa el título de ese reportaje ("Vida inármonica de Efraím de la Cruz" 15). 
corrientes, de gente "poco común". Todas las figuras que protagonizan las vidas, en este caso, "extraordinarias" vivieron durante el gobierno de los conservadores y algunas están ambientadas explícitamente durante la dictadura del General Rafael Reyes (1904-1909). En ese sentido, si recordamos su contexto de publicación inicial en Mundo al Día, estas escrituras de vidas son un mecanismo para articular una oposición. Pero, visto de otro modo, cuando son publicadas por segunda vez, se podría decir que articulan otro gesto. Ya han pasado nueve años del retorno al poder por parte de los liberales, facción política a la que Osorio Lizarazo se adscribió y participó desde el espacio de las letras, la intelectualidad y el servicio público. De este modo, se puede plantear que volver a publicar perfiles de estos seres extraordinarios, recuerda también el fracaso de la República Liberal, desde la perspectiva del periodista.

Françoise Dosse (2012) señala en "La biografía bajo la prueba de la identidad narrativa" que

Hoy en día, lo que se expresa con la nueva pasión biográfica contemporánea, no es la figura del mismo, la de la Historia magistra vitae, la del culto a la vida ejemplar, sino una nueva preocupación por el estudio de la singularidad y una atención particular hacia los fenómenos emergentes, que son considerados como objetos dignos de ser prensados gracias a su complejidad y a la imposibilidad de reducirlos a esquemas mecánicos. (257)

Aunque puede parecer contradictorio, resulta interesante hacer el ejercicio de señalar algunos de los puntos en común de las figuras biografiadas que, no obstante, se presentan con sus propias particularidades. Jacinto Albarracín, Juan Arana Torrol, Efraím de la Cruz, Cuchuco y Tulio F. Sánchez tienen una pasión o una obsesión por alguna causa. Albarracín con la lucha social y política, Efraím de la Cruz con conocer y ofrecerle una cena a Rubén Darío, Sánchez detesta a los alemanes. A excepción de Tulio F. Sánchez, quien era "diplomado en divinidades y curaciones metafísicas", todos fueron, en algún momento, revolucionarios. El perfil de Jacinto Albarracín, en palabras del cronista, tuvo "una vida opaca, pero digna de admiración [...] fundó en Colombia el primer Soviet auténtico en fuga de la tiranía del General Reyes" ("La vida extraordinaria de Jacinto Albarracín" 429 y 430).

Cuchuco, por su parte, "fue una figura central de la vida bogotana" y hasta el apogeo de la dictadura del general Reyes "había recorrido las 
calles limpiando el calzado de los revolucionarios de los Mil Días” y era "desertor de la campaña del Atlántico" ("Las vidas sencillas y extraordinarias. Cuchuco" 371). No obstante, Cuchuco también fue un protegido del dictador y gracias a su relación con él, se hizo famoso en el mundo social bogotano. En este contexto, son figuras emblemáticas de la resistencia, la lucha social y política, a pesar de que casi no sean recordados por nadie, a excepción del cronista. En cambio, la vida de Arana Torrol es extraordinaria porque heredó la receta para hacer explotar el Lusitania en la Primera Guerra Mundial. Además, todos están relacionados de alguna forma al desarrollo de los periódicos, ya sea como fundadores o colaboradores. También son escritores de versos, de libros, de novelas, de estudios, etc., incluso algunos son amigos de Rubén Darío. Efraím de la Cruz viaja a París solamente para ofrecerle una cena al poeta. Sin embargo, también son figuras -exceptuando a Sánchez y Cruz-, seniles, que vagan por la ciudad, desempleados, enfermos o que ya han muerto. Juan Albarracín, por ejemplo, "quiere un pedazo de pan y un abrigo para su vejez desamparada" ("La vida extraordinaria de Jacinto Albarracín" 434). En el año 1939, el cronista ya se daba cuenta de que sus opciones de tener un mejor puesto de trabajo o una mejor remuneración estaban lejanas. A pesar de relacionarse con los líderes liberales, nunca fue considerado para puestos de figuración pública. Por lo tanto, desde ese prisma, Osorio Lizarazo convierte estas vidas extraordinarias en un mecanismo para protestar, en esta ocasión, contra los líderes liberales como Eduardo Santos o Jorge Eliécer Gaitán, y también contra el liberalismo de derecha. ¿Cuántas vidas extraordinarias no habían luchado por la llegada de los liberales al poder y no estaban siendo invitados a participar de los beneficios de la nueva era?

"Helios no se ha avergonzado de su propia vida jamás, porque la ha hecho espontánea y de una sinceridad perfecta. Está a gusto en un puesto muy humilde dentro de la burocracia, cuyo estipendio le permite atender precariamente a su propia subsistencia" ("Vidas extraordinarias. Efraím de la Cruz" 478), señala el cronista cuando escribe de Efraím de la Cruz, un revolucionario de las primeras décadas del siglo XX. Por un lado, inmediatamente es posible indicar la función de espejo distorsionado que cumple Efraím de la Cruz. Osorio Lizarazo es otro escritor más, como los chilenos Teófilo Cid y Armando Méndez Carrasco y el mexicano Salvador Novo, por mencionar algunos ejemplos, que pasó gran parte de su vida trabajando en el servicio público y muchos de cuyos trabajos publica- 
dos se vinculan con este oficio, el del empleado público que escribe de historia, manuales, informes y otros documentos. Por lo tanto, también se adscribe a la maquinaria burocrática y desde ese lugar produce una gran parte de su corpus que no entra dentro de su escritura literaria. En la década de los treinta y parte de los años cuarenta, Osorio Lizarazo trabaja para el Estado como relator en la Cámara de Representantes, dirige el Diario Nacional, es parte del equipo de "intelectuales liberales encargados de la política cultural de masas y la política del libro coordinados por el Ministerio de Educación y la Biblioteca Nacional" (Calvo Isaza s/p, párrafo 39), es Secretario privado del Ministro de Guerra, de la Contraloría General de la República y parte de los redactores de la página editorial del El Tiempo, entre otros cargos. Pero todos los puestos que tuvo en la burocracia estatal fueron menores en comparación a los obtenidos por otros de sus camaradas liberales. Es dudoso que el cronista haya estado a gusto en los diversos puestos que ocupó, pues como señalan quienes han investigado su escritura (Calvo Isaza, 2013; Vanderhuck Arias, 2012), Osorio Lizarazo siempre deseó dedicarse a la literatura y no a ser un funcionario público de segunda categoría. No obstante, por otro lado, el trabajo gustoso de Helios recubre en el espacio público el malestar del cronista. En ese mismo sentido, intuimos que Osorio Lizarazo intenta instalarse también dentro de la esfera de los intelectuales de la década de los treinta como una figura honesta ("espontánea y sincera") ("Vidas extraordinarias. Efraím de la Cruz" 478) en un contexto dominado por las negociaciones y reparticiones de cargos y puestos, en oposición a las vidas de figuras políticas más prominentes cuya espontaneidad y sinceridad pone en entredicho. Del mismo modo, continúa el cronista señalando de Efraím de la Cruz:

Quienes han vivido su propia vida son los que han modificado el curso de la historia. Quienes hacen ostentación de su propia sensibilidad han creado las grandes teorías filosóficas y las expresiones de arte. Pero estas rutas solo pueden transitarse a base de talento. La vida sin talento no tiene derecho a seguir sus propios derroteros. (475)

La escritura de la vida de Efraím de la Cruz adquiere, por momentos, características de vida ejemplar: es revolucionario y poeta, al mismo tiempo que hombre de prensa. Cobra forma en Helio el intelectual que ya con José Martí había adquirido cierto prestigio, aquel que combate con la pluma y el fusil. Asimismo, el ser revolucionario adquiere un valor 
que debe ser destacado. En los perfiles de El Tiempo, la condición de revolucionario, en más de un personaje, es también una forma de protestar ante los lentos cambios que hasta la fecha estaba desarrollando la República Liberal.

De las figuras que llevan la etiqueta de "vidas extraordinarias", Tulio F. Sánchez es la figura más disonante, pues no es revolucionario, no lo fue. Al contrario, él encarna la figura del propietario, quien tiene tierras y fincas en Panamá. Es también el único al que el cronista accede principalmente por la lectura de sus libros, entre ellos, Colombia hacia la luz y Transformación Mundial. La vida de Tulio F. Sánchez es la última vida extraordinaria que se publica en El Tiempo el año 1940 y le permite a Osorio Lizarazo cerrar el camino comenzado con Albarracín. Si con la vida Albarracín se retrocede a la prehistoria de estas historias de vidas, es decir, suponiendo que la historia comienza el año 1930 con la toma de poder por parte de los liberales, el último párrafo que cierra el perfil de Tulio F. Sánchez, que ocurre en el presente de la narración, le permite a Osorio Lizarazo, en palabras de Sánchez, afirmar su posición dentro del contexto político y gubernamental. Dice Sánchez: "No, de ninguna manera aceptaré puestos de representación. Pero si el gobierno me llama a colaborar en alguno de los servicios públicos, en la dirección de la policía Nacional [...] Es muy posible que no pudiera negarme a una perentoria exigencia, en esta hora de peligro" ("Las vidas extraordinarias. Tulio F. Sánchez" 494). Sin embargo ese ofrecimiento, al parecer, nunca llegó para Tulio F. Sánchez porque ahí se cierra el perfil, no obstante, estamos ciertos que a Osorio Lizarazo tampoco. Como sea, estas historias forjan también ciertos modelos de masculinidad: “[...] transcurrió la infancia de Helios, orientada hacia la rebeldía que fue la esencia de su vivir inquieto. Aprendió desde entonces a tomar aguardiente y a sentirse incómodo dentro de su propio ambiente" ("Efraím de la Cruz" 476-477) , su "adolescencia [...] transcurrió en El Espectador, bajo el comando de aquel varón ejemplar, maestro de generaciones [se refiere a Fidel Cano]" ("Vidas extraordinarias. Efraím de la Cruz" 477). Por su parte, Juan Ana Torrol “[e]s revolucionario. Peleó en la guerra civil. Escribió en periódicos. Publicó una novela" ("Vidas extraordinarias. El hombre que voló el 'Lusitania"' 439). De este modo, por un lado construye un imaginario de hombres profesionales, vinculados a las letras y, sobre todo, hombres de acción, quienes se diferencian con el modo de hacer política de la oligarquía liberal y, por lo tanto, se les concede un lugar dentro de estas vidas 
extraordinarias y, por lo tanto, como vidas ejemplares ante un contexto de crisis política dentro del liberalismo.

En “Biografía de una crisis política”, publicada en 1946, Osorio Lizarazo se aboca a criticar el "movimiento de la restauración" (556-564) liderado por Gaitán, quien intentó superar la crisis del liberalismo, cuyo origen estaba, a su vez, en la oligarquía liberal. Por su parte, la redacción de $E l$ Tiempo no se hizo responsable de las ideas vertidas por Osorio Lizarazo (556). Entre las varias explicaciones de la situación, Osorio Lizarazo es tajante en explicar que si bien Gaitán estaba perfilándose como un buen candidato presidencial, en cuanto a esta crisis que el mismo Gaitán convocó para que fuera solucionada, el cronista es enfático en decir que el líder liberal "como hombre de acción es inepto e incapaz", a diferencia de sus habilidades "como agitador y como demagogo" (559). Más enfático es todavía en señalar que Gaitán no es un hombre de acción, pues no ejecuta, no tiene programa. Esa idea contrasta reveladoramente con las diversas e intensas actividades de los hombres y mujeres que protagonizan los perfiles de El Tiempo. Ellos sí son, efectivamente, revolucionarios, hombres y mujeres de acción. Luego, nos dice la historia, que Gaitán fue candidato presidencial, pero ya a mediados de la década del cuarenta, Osorio Lizarazo tenía su propio balance, despliega toda su descarga contra la República Liberal y en ella se hacen explícitos ciertos valores que son posibles de detectar en los perfiles de muchos de los personajes sobre los que escribió:

No soy, ni he sido, ni seré nunca un político. Amo el trabajo rápido, eficaz y oportuno y me desespero, como si recibiera una afrenta personal, cuando me obligan, para que los pobres empleados públicos justifiquen su razón de ser en la burocracia, a dar vueltas, a esperar antesalas, a llenar formularios inútiles para reclamar una carta o para obtener una información que me sirva para un artículo. ("Biografía de una crisis política” 562-563)

Los perfiles también destacan por usar cierta jerga que no está tan presente en los reportajes de las décadas del veinte. Personajes profesionales, o que hicieron de sus oficios una profesión o que destacaron como profesionales cobran relevancia, insinuando la importancia del mérito, la profesión y el oficio, es decir, experiencias fundamentales para la consolidación de la clase media y para la inserción de estos nuevos actores en una sociedad moderna. Sin embargo, nada de eso estaba, al parecer, siendo considerado en la maquinaria del estado: 
Y cuando se hablaba de que era profundamente inmoral el hecho de que un individuo, sabiéndose incapaz de cumplir con determinadas funciones administrativas, aceptaba posiciones inmerecidas sola para ganarse el sueldo, traicionando la fe popular, el doctor Gaitán anunciaba la necesidad de la restauración de la moral política, perdida en éstos y parecidos incidentes de la administración, que serían profunda y desastrosamente consecuenciales. ("Biografía de una crisis política" 557)

Esa característica se conjuga con su resistencia, su lucha política y su cercanía con las ideas de izquierda. Jacinto Albarracín, después de su periplo, "regresó a Bogotá, donde volvió a ejercer su profesión de abogado" ("La vida extraordinaria de Jacinto Albarracín” 432). Por su parte, Julia Ruiz, quien domina espíritus en la entrevista, en su perfil en cambio, consigue una profesión porque logró adquirir "la mística política en su grado exaltado y casi delirante". Y, además, "era profundamente izquierdista" ("La vida misteriosa y sencilla de Julia Ruiz" 315 y 316)

El periodista también duda sobre lo que significa escribir una vida, pero cuando está escribiendo los perfiles para El Tiempo parece más inspirado en la situación política que en los desafíos de la escritura biográfica. Sin embargo, la reflexión está ahí: "Biófilo Panclasta es un personaje gigantesco para una biografía que no se escribirá nunca. Anarquista, terrorista, nihilista, amigo de Gorki, co-autor del atentado contra el zar Alejandro de Rusia, y a veces dinamitero" ("La vida misteriosa y sencilla de Julia Ruiz" 316). O cuando escribe de Roberto Rojas Gómez, "el último romántico", señala:

Hace tres o cuatro días murió Roberto Rojas Gómez. Nada os dirá este nombre humilde y trivial, que no ocupó las columnas de las revistas intelectuales, ni mereció los aplausos de la crítica, ni fue general, ni doctor en nada, ni resonante empleado público, ni miembro de instituciones culturales o de beneficencia. Todo en él fue ser Roberto Rojas Gómez. ("Las vidas humildes. El último romántico" 351).

No obstante, ese "ser" que subraya el escritor colombiano para iniciar el perfil, después es desmentido al destacar su enorme trabajo dedicado a la escritura de libros y su encierro en bibliotecas. Todos los personajes de Osorio Lizarazo están llenos de acciones, de pasados, y son, también, multifacéticos. 
En la introducción al libro Life Stories. Profiles from The New Yorker David Remnick (2001) señala que "One quality that runs through nearly all best Profiles [...] is a sense of obsession. [...] In every great Profile, too, the writer is equally obessed" (xi). Si bien por medio del uso de esta cita no quisiera plantear que los perfiles escritos por José Antonio Osorio Lizarazo sean los mejores dentro del universo de perfiles y retratos colombianos o latinoamericanos de mediados de siglo XX, me interesa la idea de la "obsesión" en la escritura de perfiles y biografías. Una obsesión por ciertos personajes, la reescritura de sus vidas y una predilección por el género biográfico. Es una obsesión la del periodista de volver a recurrir a estos personajes bajo el formato del perfil y en otro contexto sociopolítico. Estas escrituras revelan una obsesión con un tipo de personajes, a quienes les hace un seguimiento y, desde la invisibilización inicial, los ubica en un lugar de agencia política, de trascendencia.

\section{Refrencias bibliográficas}

Arfuch, Leonor. El espacio biográfico. Dilemas de la subjetividad contemporánea. Buenos Aires, Fondo de Cultura Económica, 2010.

Bruno, Paula. Presentación dossier "Biografía e historia. Reflexiones y perspectivas". Anuario IEHS, no. 27, 2012, pp. 155-162.

Calvo Isaza, Oscar Iván. Las biografías de nadie. Presentación y edición de Óscar Calvo Isaza. Catálogo de la Exposición "La ciudad innominada de J.A. Osorio Lizarazo". Biblioteca Nacional de Colombia, Bogotá, agosto-diciembre 2013.

Darrigrandi Navarro, Claudia. Huellas en la ciudad: Figuras urbanas en Buenos Aires y Santiago de Chile, 1880-1935. Santiago, Editorial Cuarto Propio, 2014.

Devés, Eduardo. El pensamiento latinoamericano en el siglo XX. Entre la modernización y la identidad. Tomo I. Buenos Aires, Biblios, Centro de Investigaciones Diego Barros Arana, Santiago, 2000.

Dosse, Françoise. "La biografía bajo la prueba de la identidad narrativa”. El giro reflexivo de la historia. Recorridos epistemológicos y atención a las singularidades. Santiago, Ediciones Universidad Finis Terrae, 2012.

Hobsbwam, Eric. Gente poco corriente. Resistencia, rebelión y jazz. Barcelona, Editorial Crítica, 1999. 
Melo, Jorge Orlando. "Eduardo Santos”. Colombia es un tema. 13 noviembre 2015. http://www.jorgeorlandomelo.com/eduardosantos. htm

Mutis Durán, Santiago. Introducción. Novelas y crónicas. José Antonio Osorio Lizarazo. Selección e introducción de Santiago Mutis Durán. Bogotá, Colombia, Instituto Colombiano de Cultura, 1978. XI-LXXXIV.

Neira, Edison. La gran ciudad latinoamericana: Bogotá en la obra de José Antonio Osorio Lizarazo. Medellín, Colombia, Fondo editorial EAFIT, 2004.

Osorio Lizarazo, J.A. La cara de la miseria. Bogotá, Talleres de Ediciones Colombia, 1926.

- "Biofilo Panclasta, el anarquista colombiano amigo y compañero de

Lenin, que conoció los horrores de la estepa en Siberia". Novelas y crónicas. Selección e introducción de Santiago Mutis Durán. Bogotá, Colombia, Instituto Colombiano de Cultura, 1978, pp. 364-370.

_ _ "La vida extraordinaria de Jacinto Albarracín. El primero en América que ensayó un gobierno de soviet". Novelas y crónicas. Selección e introducción de Santiago Mutis Durán. Bogotá, Colombia, Instituto Colombiano de Cultura, 1978, pp. 426-434.

. “Las vidas extraordinarias. Tulio F. Sánchez". Novelas y crónicas. Selección e introducción de Santiago Mutis Durán. Bogotá, Colombia, Instituto Colombiano de Cultura, 1978, pp. 488-494. "Las vidas sencillas y extraordinarias. Cuchuco". Novelas y crónicas. Selección e introducción de Santiago Mutis Durán. Bogotá, Colombia, Instituto Colombiano de Cultura, 1978, pp. 371-375. - "Pablo Emilio Mancera, el hombre que durante 40 años publicó un periódico del que era el único lector”. Novelas y crónicas. Selección e introducción de Santiago Mutis Durán. Bogotá, Colombia, Instituto Colombiano de Cultura, 1978, pp. 326-336. - "Vidas extraordinarias. Efraím de la Cruz". Novelas y crónicas. Selección e introducción de Santiago Mutis Durán. Bogotá, Colombia, Instituto Colombiano de Cultura, 1978, pp. 475-478. " "Vidas extraordinarias. El hombre que voló el 'Lusitania' y precipitó el fin de la guerra europea”. Novelas y crónicas. Selección 
e introducción de Santiago Mutis Durán. Bogotá, Colombia, Instituto Colombiano de Cultura, 1978, pp. 435-445.

Novelas y crónicas. Selección e introducción de Santiago Mutis

Durán. Bogotá, Colombia, Instituto Colombiano de Cultura, 1978.

Osorio Lizarazo, José Antonio. “A los 18 años de apostolado estéril”. Mundo al Día. 19 de febrero de 1927, pp. 22.

. “Albarracín revolucionario y escritor". Mundo al Día. 26 de marzo de 1927, pp. 18.

. "Biografía de una crisis política. La aventura de un gaitanista”. Novelas y crónicas. Selección e introducción de Santiago Mutis Duran. Bogotá, Colombia: Instituto Colombiano de Cultura, 1978, pp. 556-564.

__ . "El hombre que podría salvar el país". Mundo al Día. 12 de febrero de 1927, pp. 23.

___. "La vida misteriosa y sencilla de Julia Ruiz". Novelas y crónicas. Selección e introducción de Santiago Mutis Durán. Bogotá, Colombia, Instituto Colombiano de Cultura, 1978, pp. 314-317.

_. "Las vidas humildes. El último romántico que vivió sobre la tierra". Novelas y crónicas. Selección e introducción de Santiago Mutis Durán. Bogotá, Colombia, Instituto Colombiano de Cultura, pp. 1978. 351-357.

. "Perseguido por todos los gobiernos". Mundo al Día. 7 de marzo de 1927, pp. 12.

. "Se prepara una contienda universal a la que pondrá fin un superhombre. Una mujer en Bogotá domina cien millones de espíritus". Mundo al Día. 2 de abril de 1927, pp. 22-23.

__. “Un poeta que espera la consagración”. Mundo al Día. 22 de enero de 1927, pp. 25.

“Un Sancho bogotano socarrón y poeta. Cuchuco fundó el gremio de los ayudantes de la prensa". Mundo al Día. 12 de julio de 1927 , pp. 15.

__. "Vida inarmónica de Efraím de la Cruz". Mundo al Día. 9 de abril de 1927, pp. 16.

Remnick, David. Introduction. Life Stories. Profiles from The New Yorker. New York, The Modern Library, 2001. 
Rosendo, Belén. "El perfil como género periodístico". Communication \& Society, vol. 10. No. 1, 1997, pp. 95-115.

Vanderhuck Arias, Felipe. La literatura como oficio. Jose区Antonio Osorio Lizarazo 1930-1946. Medellín, Colombia, La Carreta Editores, Universidad ICESI, 2012. 